(C) Dr W. Junk Publishers, Dordrecht - Printed in the Netherlands

\title{
A benthos inventory in the Zeeland Coastal zone (the Netherlands)
}

P. Seip ${ }^{1}$, R. Brand ${ }^{1}$, J. v.d. Meer ${ }^{2}$, A. C. Smaal ${ }^{2}$, F. Creutzberg1, A. Engelberts ${ }^{1} \&$ K. Hoek ${ }^{2}$

'NIOZ: The Netherlands Institute for Sea Research, Texel

${ }^{2}$ RWS: Rijkswaterstaat, Tidal Water Division, Middelburg

In 1984 The Delta Department of Rijkswaterstaat (Ministry of Transport and Public Works) initiated a project in cooperation with the Netherlands Institute for Sea Research (NIOZ) and The State University of Gent-Belgium to estimate species abundance and distribution of macro- and meiobenthos in the Coastal Waters of Zeeland ( $<15 \mathrm{~m}$ depth).

In this area considerable hydrological and morphological changes occur due to the coastal engineering projects performed in the Rhine-Scheldt delta (the Delta project).

The benthos program is part of an integrated research project to describe and monitor the ecological development of this coastal zone. Surveys of meio- and macrofauna have been carried out in sept-nov. 1984, april-may 1985 and sept-oct. 1985, by sampling with a Reineck box corer $\left(0.068 \mathrm{~m}^{2}\right)$ or a Van Veen grab $\left(0.2 \mathrm{~m}^{2}\right)$.

At the start selection of 65 stations was based on available knowledge of abiotic conditions. At each station 5 sample-units have been taken. Using the macrofauna density data of this first survey the macrofauna group was able to discern TWINSPAN-cluster members (stations) in spatial groups (strata).

As a consequence one decided to use a stratified random sampling strategy for the second and third survey: \pm 200 sample-units were distributed over respectively 6 and 10 strata. So in all cases information from the preceeding survey was used to refine the sampling strategy of the following.

This strategy yields statistically reliable estimates for the densities of the more common species not concerning stations but concerning the strata and the whole area.

At every sample point sediments have been sampled for among others grain-size analysis.

On the poster, besides a few pictures of sampling and processing macro-benthos, the ordered samplespecies matrices and the corresponding spatial distribution of the cluster members (sample-units) together with the deduced strata have been shown. 